\title{
A Very Rare Cause of Anal Atresia: Currarino Syndrome
}

\author{
Sevgi Buyukbese Sarsu ${ }^{\mathrm{a}, \mathrm{c}}$, Mehmet Ergun Parmaksiz ${ }^{\mathrm{a}}$, Esra Cabalar ${ }^{\mathrm{b}}$, Ali Karapur ${ }^{\mathrm{a}}$, \\ Cihat Kaya ${ }^{b}$
}

\begin{abstract}
Currarino syndrome (triad) is an extremely rare condition characterized by presacral mass, anorectal malformation, and sacral bone deformation. The complete form of this syndrome displays all three irregularities. Herein, we report a male case who was admitted to our hospital with symptoms of urinary system infection and persistent constipation 2 years after colostomy operation performed with the indication of rectovestibular fistula and anal atresia, diagnosed as Currarino syndrome based on imaging modalities. In a patient who was admitted because of the presence of anal atresia, in order to preclude potential complications, probable concomitancy of this syndrome should not be forgotten. Early diagnosis is important for the prevention of meningitis, urinary tract infections, and malignant change.
\end{abstract}

Keywords: Currarino syndrome; Presacral mass; Anorectal malformation; Sacral bone deformation; Urinary tract infections

\section{Introduction}

Currarino syndrome (CS) is a very rarely seen condition which is termed as Currarino triad. In fact, from 1981 on, nearly 300 cases have been published. It is a hereditary pathology which is characterized by a triad of sacrococcygeal bone defect, presacral mass, and anorectal malformation. Sacrococcygeal bone defect is always a component of this syndrome. When it is associated with all of these three anomalies, it is called complete form, while in the presence of one or two components, it is named incomplete form. Our case was a rarer complete form. MNX1 gene (motor neuron and pancreas homeobox 1, HGNC ID: 4979) mutations have been reported in all cases with familial Currarino triad. The condition demonstrates fa-

Manuscript accepted for publication February 23, 2016

aDepartment of Pediatric Surgery, Cengiz Gokcek Obstetrics and Children's Hospital, 27560, Sehitkamil, Gaziantep, Turkey

bDepartment of Radiology, Ersin Arslan Training and Research Hospital, 27090, Sehitkamil, Gaziantep, Turkey

${ }^{\mathrm{c} C o r r e s p o n d i n g ~ A u t h o r: ~ S e v g i ~ B u y u k b e s e ~ S a r s u, ~ D e p a r t m e n t ~ o f ~ P e d i a t r i c ~ S u r-~}$ gery, Cengiz Gokcek Obstetrics and Children's Hospital, 27560, Sehitkamil, Gaziantep, Turkey. Email: sarsusevgi@yahoo.com.tr

doi: http://dx.doi.org/10.14740/jocmr2505w milial predisposition, and has a autosomal dominant inheritance pattern [1]. Nearly $30 \%$ of the cases with CS are sporadic [2]. This triad which was firstly described by Currarino et al is asymptomatic in more than $33 \%$ of the affected children. Symptoms such as intractable constipation, urinary retention, incontinence, and bowel obstruction in infancy are frequently associated with this presentation. Rarely association of Hirshsprung disease (HD) with CS has also been reported [3]. It can also accompany urogenital anomalies. Indeed, in more than $15 \%$ of the cases with Currarino triad, concomitant Mullerian duct anomalies are detected. General incidence of Mullerian duct anomalies has been reported as 7\% [4]. Neonatal diagnosis is rarely established.

Cases with sacral agenesia should be investigated as for presacral masses and anorectal changes [5]. For cases with suspect CS, multidisciplinary approach at an early stage is important [6]. In the presence of anal atresia, prevention of potential complications is possible with raising awareness about this syndrome.

\section{Case Report}

A 2-year-old male infant was admitted to our hospital with inability to urinate and intractable constipation. From his medical history, it was learnt that $24 \mathrm{~h}$ after his birth, he had undergone colostomy operation with the indication of anal atresia and rectovestibular fistula. On physical examination, any abnormal finding apart from abdominal distension was not detected. Complete urinalysis revealed abundant leukocytes and erythrocytes in urine. The plain abdominal X-ray performed in the standing position demonstrated a defect at the right lower side of the sacrum, and a dysplasic image displayed deviation to the left (scimitar sacrum) (Fig. 1). On abdominopelvic ultrasound, a multilocular septated cystic lesion measuring $5.7 \times 6$ $\mathrm{cm}$ in the presacral area was detected (Fig. 2). On abdominal tomogram, hypoplasic appearance of the right sides of $\mathrm{S} 3$, and vertebras inferior to S3, leftward deviation of sacrum (scimitar sacrum), and a presacral cystic lesion were detected (Fig. 3). On lumbosacral magnetic resonance imaging (MRI), widening of the right S3-S4 and S4-S5 neural foramens, and a multilocular, septated anterior sacral meningocele (ASM) which continued with sacral spinal canal anteriorly displaced bladder, and rectum were observed (Fig. 4).

We performed posterior sagittal anorectoplasty (PSARP). The patient was also operated in the Clinics of Neurosurgery with the indication of ASM. 




Figure 1. An abdominal radiograph: a defect at the right lower side of the sacrum, and a dysplasic image displaying deviation to the left (scimitar sacrum).

\section{Discussion}

This syndrome which was named after scientist Guldo Currarino who first discovered this triad is characterized by a sacral bone defect, a congenital hindgut anomaly, and a presacral tumor. This syndrome has been reported to stem from the HLXB9 gene mutations on the chromosome 7. Therefore,

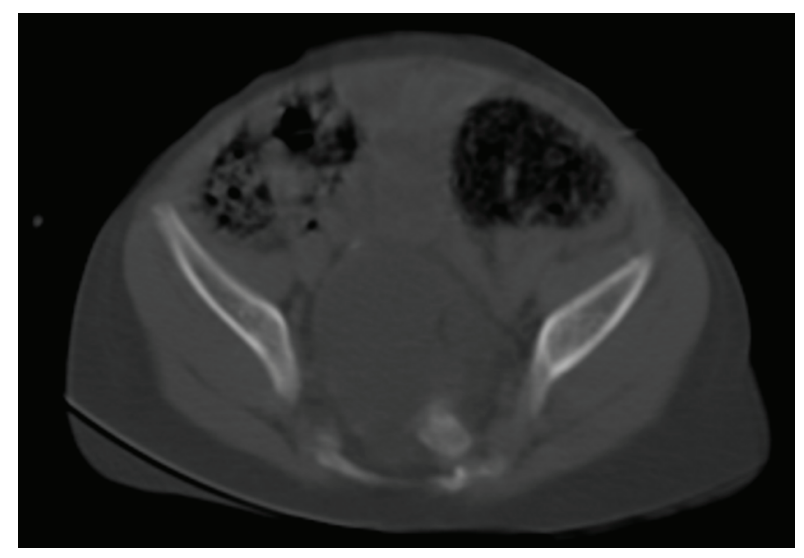

Figure 3. Abdominal tomogram: hypoplasic appearance of the right sides of S3, and vertebras inferior to S3, leftward deviation of sacrum (scimitar sacrum), and a presacral cystic lesion.

presacral masses and sacral ageneses w/o anorectal anomalies are suggestive of possible familial CS [5].

Presacral mass which accompanies CS may consist of a teratoma, a hamartoma, a neuroenteric cyst, anterior meningocele or a combination of these four entities [7]. Sacral agenesis is defined as partial or complete congenital absence of sacrum. Most cases are asymptomatic. It has been reported that presacral mass results in symptoms such as intractable constipation, urinary incontinence, sacral anesthesia, paraesthesia of the lower extremities, disturbance of anal sphincter control, etc. Among them, constipation is the most commonly reported symptom [8]. Other symptoms are related to recurrent urinary tract infections, nausea, headache, and lumbar pain [8]. In our case, clinical symptoms of urinary infection were associated with constipation. Though rarely its association with

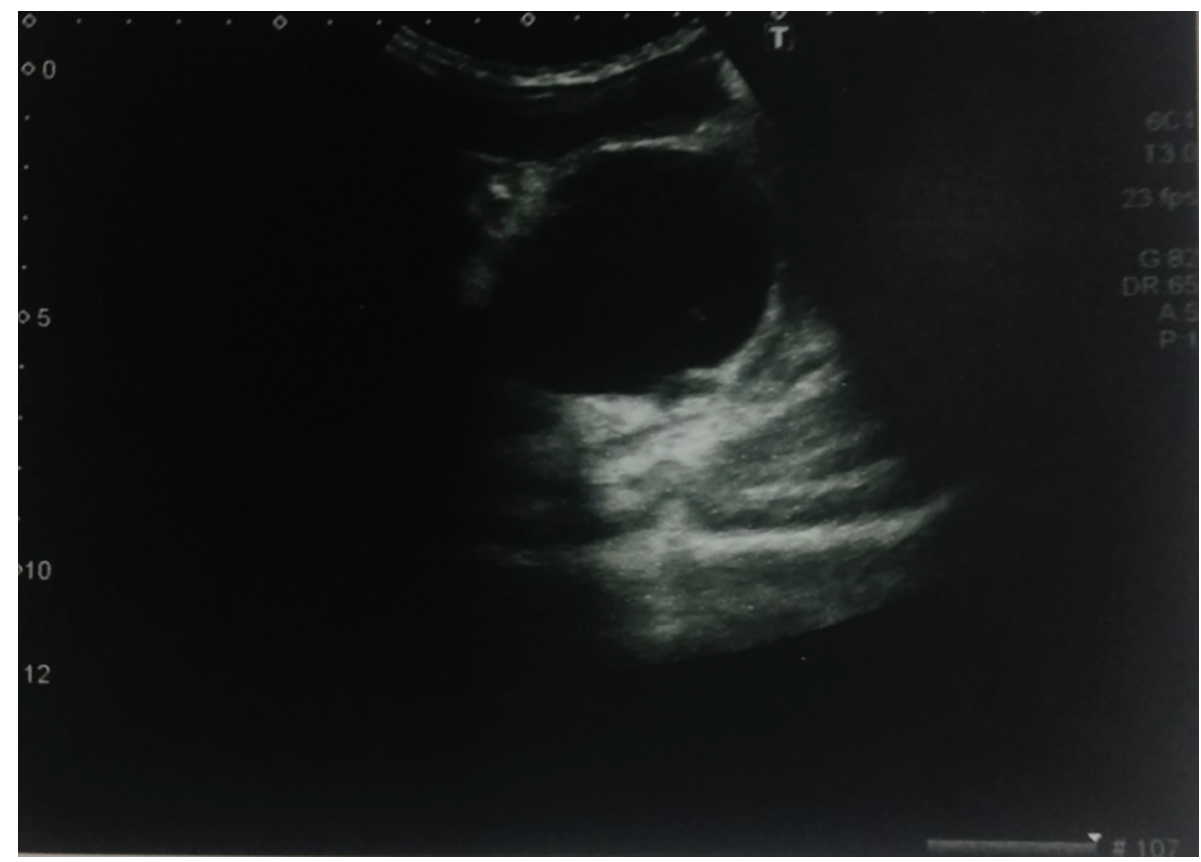

Figure 2. An ultrasound examination revealed a multilocular septated cystic lesion measuring $5.7 \times 6 \mathrm{~cm}$ in the presacral area. 

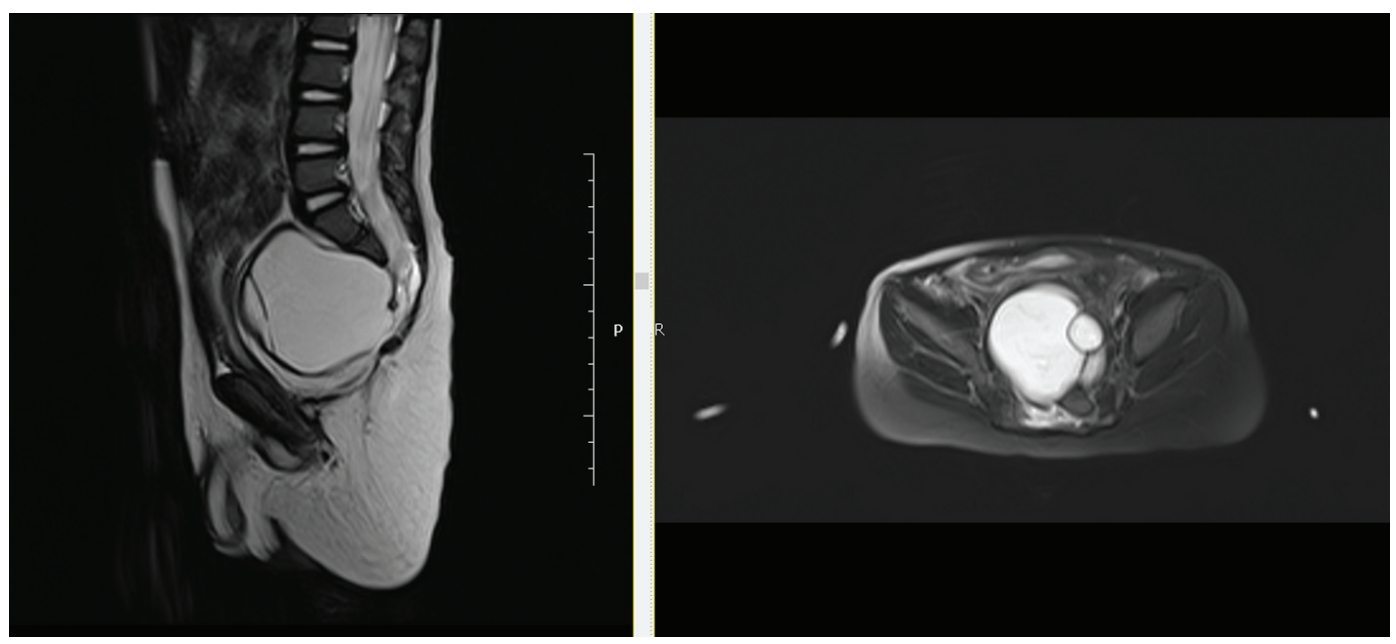

Figure 4. Lumbosacral MRI: widening of the right S3-S4 and S4-S5 neural foramens, and a multilocular, septated anterior sacral meningocele (ASM) which continued with sacral spinal canal anteriorly displaced bladder, and rectum were observed.

HD has been reported [9]. Still, presence of CS was reported in an adult case with chronic anal fistula [6]. In the diagnosis and follow-up of CS, radiological imaging modalities such as ultrasonography (US), computed tomography (CT), and MRI play a vital role [10].

Kassir et al reported MRI as a specific and sensitive noninvasive diagnostic tool in cases with anorectal malformation [6]. MRI can be used reliably in the diagnosis of this syndrome, associated mass lesions, and other pathologies, and also during post-treatment follow-up period of cases with CS [10].

Regardless of its anatomical characteristics, presacral mass should be completely removed during surgical resection. In our case, anterior meningocele was detected, and sacral laminectomy was applied through retroperitoneal approach. In these cases, in order to avoid serious neurological complications, the connection between spinal canal and tumor should not be overlooked. Though rarely, since its malignant transformation into teratoma has been reported, multidisciplinary approach is very important in cases with CS which can result in morbidities and mortality.

\section{Conclusion}

Anal atresia can be one of the components of Currarino triad. In a patient who was admitted because of the presence of anal atresia, in order to preclude potential complications, probable concomitancy of this syndrome should not be forgotten.

\section{Source of Support}

None.

\section{Conflict of Interest}

None.

\section{Funding}

None.

\section{Author Contributions}

Sevgi Buyukbese Sarsu has contributed to writing this paper. Sevgi Buyukbese Sarsu, Mehmet Ergun Parmaksiz, Esra Cabalar, Ali Karapur and Cihat Kaya have contributed to data collections.

\section{References}

1. Markljung E, Adamovic T, Cao J, Naji H, Kaiser S, Wester T, Nordenskjold A. Novel mutations in the MNX1 gene in two families with Currarino syndrome and variable phenotype. Gene. 2012;507(1):50-53.

2. Merello E, De Marco P, Ravegnani M, Riccipetitoni G, Cama A, Capra V. Novel MNX1 mutations and clinical analysis of familial and sporadic Currarino cases. Eur $\mathbf{J}$ Med Genet. 2013;56(12):648-654.

3. Furuta S, Sato H, Hamano S, Kitagawa H. Currarino syndrome associated with Hirschsprung's disease: Case report and literature review. J Ped Surg Case Reports. 2015; 3:308-311.

4. Robbins JB, Broadwell C, Chow LC, Parry JP, Sadowski EA. Mullerian duct anomalies: embryological development, classification, and MRI assessment. J Magn Reson Imaging. 2015;41(1):1-12.

5. Perez Vega-Leal C, Sainz Gomez C, Ubis Rodriguez E, Garrido-Dominguez E, Diez Fernandez A, Rubio Viguera V. Hallazgos radiologicos en el sindrome de Currarino. Radiologia. 2013;55:233-238.

6. Kassir R, Kaczmarek D. A late-recognized Currarino syndrome in an adult revealed by an anal fistula. Int J Surg Case Rep. 2014;5(5):240-242. 
7. Djordjevic I, Pejcic T, Rancic M, Radovic M, Bosnjakovic $\mathrm{P}$, Radjenovic-Petkovic T, Nastasijevic-Borovac $\mathrm{D}$, et al. Difficulties in establishing a timely diagnosis of pulmonary artery sarcoma misdiagnosed as chronic thrombo-embolic pulmonary disease: a case report. J Med Case Rep. 2009;3:64.

8. Arora P, Purai N, Rajpurkar M, Kamat D. A missed case of Currarino syndrome. Clin Pediatr (Phila).
2010;49(2):183-185.

9. Ohno K, Nakamura T, Azuma T, Nakaoka T, Takama Y, Hayashi H, Horiike M, et al. Familial Currarino syndrome associated with Hirschsprung disease: two cases of a mother and daughter. J Pediatr Surg. 2013;48(1):233-238.

10. Akay S, Battal B, Karaman B, Bozkurt Y. Complete currarino syndrome recognized in adulthood. J Clin Imaging Sci. 2015;5:10. 